\title{
Heterotopic Pregnancy- Case Report
}

\author{
S JAHAN ${ }^{\mathrm{a}}$, TR DAS ${ }^{\mathrm{b}}$, L AKTER $^{\mathrm{a}}$
}

(J Bangladesh Coll Phys Surg 2011; 29: 44-45)

\section{Introduction:}

Heterotopic pregnancy is the co- existence of an intrauterine and ectopic gestation. [1] In 1948, the spontaneous heterotopic pregnancy rate was calculated as 1 in 30 thousand pregnancies, based on an ectopic pregnancy incidence of $0.37 \%$ and dizygous twining rate of $0.8 \%$. [2] In the 1980 's, the number raised to 1 in 10 thousand due to an increased ectopic pregnancy rate. [3] Today, heterotopic pregnancies actually occur 1 in 3889 [4] to 1 in 6778 [5] pregnancies. In a review of 66 heterotopic pregnancies by Reece et al, [3] 93.9\% were tubal and $6.1 \%$ ovaries.

Simultaneous existence of intra- and extra uterine pregnancies poses several diagnostic pitfalls. Heterotopic pregnancies are diagnosed in most cases after the development of symptoms and clinical diagnosis, and $50 \%$ of patients are admitted for emergency surgery following rupture. ${ }^{1}$

Similar to tubal ectopic pregnancies, the most common complaint is lower abdominal pain, occurring in $81.8 \%$ of patients. Peritoneal irritation occurs in $43.9 \%$ and vaginal spotting in $31.8 \% .^{3}$ Routine Ultrasound detects only about $50 \%$ of tubal heterotopic pregnancies and the remainder is diagnosed at laparoscopy or laparotomy when patients become symptomic. ${ }^{1}$ Serial levels of the â-subunit of human chronic gonadotropin ( $\beta$-HCG) are not helpful due to the concomitant intrauterine pregnancy.

If patients are hemodynamically unstable, an exploratory laparotomy is warranted. If the diagnosis is suspected

a. Dr. Samsad Jahan, Dr. Latifa Akter, Department of Obstetrics and Gynaecology, BIRDEM, Dhaka, Bangladesh.

b. Dr. Trypti Rani Das, Department of Obstetrics and Gynaecology, BSMMU, Dhaka, Bangladesh

Address of Correspondence: Dr Samsad Jahan, Associate Professor \& Consultant, Ibrahim Medical College \& Department of Gynecology \& Obstetrics, BIRDEM Hospital, 122 Kazi Nazrul Islam Avenue, Dhaka-1000, Bangladesh, E-mail: dhcdp@dab-bd.org; samirahumaira@yahoo.com; rsharif722003@yahoo.com

Received: 12 May, 2009

Accepted: 11 June, 2010 or the patient is symptomatic but hemodynamically stable, laparoscopy can be performed. Expectant management is not recommended, since $\beta$-HCG levels cannot be monitored adequately. Systemic methotrexate rate is contra indicated if a viable intrauterine pregnancy is present. Local injection of methotrexate with potassium chloride was not successful in a small case series. $^{6}$

\section{Case Report:}

A 37 years old multigravid (G3P2) women came to a private clinic with 5 weeks of amenorrhoea with the complaints of severe lower abdominal pain, nausea and vomiting for the last 6 hours and with positive urine for pregnancy test. Her BP was 110/60 mmHg and pulse 85 beat per minute. On per abdominal examination abdomen was soft. A transabdominal Ultrasonography scan showed single early intrauterine pregnancy of 5.1 weeks duration with single fetal node. Fetal heart movement (FHM) and fetal movement (FM) not seen at scan. Fetal Biometry: GSD - $10.6 \mathrm{~mm}$.

She was advised to do a repeat scan one week later. After 8 days again she had severe lower abdominal pain with passage of clotted blood and USG scan showed missed abortion, no mass of cyst could be seen in the abdominal region and dilatation and curettage was done. Histopathology report under microscopy showed: sheets of decidual tissue, blood clot and chorionic villi . Patient was discharged from hospital on the next day. Seven days later she had severe lower abdominal pain with fainting attack at home and BP was 80/50 mmHg, pulse was 120 bpm, Pervaginal examination was done and the result was cervix soft, OS $1.5 \mathrm{~cm}$ dilated, uterus was 10 weeks pregnancy size, fornices -right fornix full and tender. No palpable mass or cyst was felt in the left fornix. USG showed bulky uterus with mild PID, a well defined cystic area and thick wall seen in the right ovary measuring about $1.8 * 1.4 \mathrm{~cm}$. A well defined fairly large mixed echogenic (Predominantly hypoechoic) focal lesion seen in the right adnexa, measuring about $6.1 * 3.8$ 
$\mathrm{cm}$, left tubo-ovarian region appears to be normal. Serum â-HCG was 4539 mIU/ml, 60 laparotomy was done. Fallopian tube on right side was enlarged. Right sided salpingectomy and left sided tubal ligation was done. Patient and her husband gave consent for ligation. There was huge amount of blood and clots into the peritoneal cavity. After peritoneal toileting and haemostasis abdomen was closed in layers. She was transfused 2 units of blood. As Patient condition was stable, she was discharged on the next day.

Hispathology of the right fallopian tube showed marked oedema in the mucosa and serosa and lumen was dilated congested and contains chorionic villi and decidual changes along with blood clot in the fallopian tube. Diagnosis- ectopic tubal pregnancy.

\section{Conclusion:}

Diagnosis of ectopic pregnancy prior to rupture is an arduous task even with the availability of many new investigative methods and imaging modalities. A high index of suspicion is necessary when dealing with women who present in early pregnancy with abdominal pain and pervaginal bleeding. The use of transvaginal ultrasonography (TVS) and Sr. â HCG level will help in earlier diagnosis because of its advantages over transabdominal ultrasonography. ${ }^{7}$
This report should create the awareness of the possibility of heterotopic pregnancy in spontaneous cycles. With the increased use of ovulation induction agents, the probability of heterotopic pregnancy should be kept in mind.

\section{Reference:}

1. Rojansky N, Sehenker JG. Heterotopic Pregnancy and assisted reproduction: an update. J Assist Reprod Genet. 1996; 13: 594-601.

2. De Voe RW, Pratt JH. Simultaneous intrauterine and extrauterine pregnancy. Am J Obstet Gynecol. 1948; 56: 11191126.

3. Reece EA, Petrie RH, Sirmans MF, Finster M, Todd WD. Combined intrauterine and extrauterine gestation: a review. Am J Obstet Gynecol. 1983; 146: 323-330.

4. Bello GV, Schonholz D, Moshirpur J etal. Combine pregnancy: the mount Sinai experience. obstet gyne col surv . 1986; 41 : 603-613.

5. Hann LE, Bachmann DM, Mc Ardle C. Co existent intra uterine and ectopic pregnancy: a reevaluation. Radiology. 1984; 152: 151-154.

6. Guirgis RR. Simultaneous intrauterine and ectopic pregnancies following in vitro fertilization and gameted intrafallopian transfer: a review of nine cases. Hum Reprod. 1990; 5: 5; 484-486.

7. Wong CM, Ganesh R, Ng Ky. Ectopic pregnancy: Uncommon presentations and difficulty in diagnosis. Med J Malaysia. 1999. Mar; 54(1): 117-119. 